\title{
Primary photoluminescence in as-neutron (electron) -irradiated n-type 6H-SiC
}

\author{
Z. Q. Zhong, D. X. Wu, ${ }^{a)}$ M. Gong, and O. Wang \\ Department of Physics, Lab of Microelectronics, Sichuan University, Chengdu, Sichuan 610064, \\ People's Republic of China
}

S. L. Shi, S. J. Xu, X. D. Chen, C. C. Ling, S. Fung, and C. D. Beling

Department of Physics, the University of Hong Kong, Pokfulam Road, Hong Kong, People's Republic of China

G. Brauer, W. Anwand, and W. Skorupa

Institut für Ionenstrahlphysik und Materialforschung, Forschungszentrum Rossendorf, Postfach 510119, D-01314 Dresden, Germany

(Received 18 April 2005; accepted 19 March 2006; published online 15 May 2006)

\begin{abstract}
Low-temperature photoluminescence spectroscopy has revealed a series of features labeled $S_{1}, S_{2}$, $S_{3}$ in $n$-type $6 \mathrm{H}-\mathrm{SiC}$ after neutron and electron irradiation. Thermal annealing studies showed that the defects $S_{1}, S_{2}, S_{3}$ disappeared at $500{ }^{\circ} \mathrm{C}$. However, the well-known $D_{1}$ center was only detected for annealing temperatures over $700{ }^{\circ} \mathrm{C}$. This experimental observation not only indicated that the defects $S_{1}, S_{2}, S_{3}$ were a set of primary defects and the $D_{1}$ center was a kind of secondary defect, but also showed that the $D_{1}$ center and the $E_{1}, E_{2}$ observed using deep level transient spectroscopy might not be the same type of defects arising from the same physical origin. (C) 2006 American Institute of Physics. [DOI: 10.1063/1.2195014]
\end{abstract}

\section{INTRODUCTION}

Silicon carbide $(\mathrm{SiC})$ is a promising wide band gap material for fabricating high-temperature, high-power, highfrequency, and irradiation hard semiconductor devices. Ion implantation is the only available method to realize selective doping in SiC. Unfortunately, some residual defects caused by ion implantation remain even after high-temperature annealing. Further, modern $\mathrm{SiC}$ devices are used very widely in radiation environments. All these aspects have motivated researchers to study defects induced by irradiation. ${ }^{1-5,7-10}$ Many irradiation-induced deep level defects in $6 \mathrm{H}-\mathrm{SiC}$ have been reported, among which the most well-known defects are the $E_{1}, E_{2}$ observed in deep level transient spectroscopy $^{1,5-8}$ (DLTS) and the $D_{1}$ center (or $L_{1}, L_{2}, L_{3}$ ) as the main signals detected by low-temperature photoluminescence (LTPL) spectroscopy. ${ }^{9,10}$ Because of their similar high thermal-stability properties, some investigators have attributed these two groups of defects to the same origin, namely the divacancy $\left(V_{C}-V_{S i}\right){ }^{1,2,9,11}$ In our previous work in which defects in $n$-type $6 \mathrm{H}$-SiC samples induced by He implantation and electron irradiation were studied using DLTS techniques, we demonstrated that different particle irradiation indeed introduced different defects. ${ }^{8}$

\section{EXPERIMENTAL}

The $n$-type $6 \mathrm{H}-\mathrm{SiC}$ samples with orientation (0001) used in this work were commercially available from CREE Research, Inc. For these samples, a nitrogen doped epilayer $5 \mu \mathrm{m}$ thick was grown on $n^{+}$-type $6 \mathrm{H}-\mathrm{SiC}$ substrate. The nitrogen donor concentrations were $9 \times 10^{15} \mathrm{~cm}^{-3}$ and 6.6

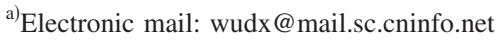

$\times 10^{18} \mathrm{~cm}^{-3}$ in the epilayer and the substrate, respectively. Three pieces of samples were used in this work, which were unirradiated, electron irradiated with electron energy of $1.7 \mathrm{MeV}$, and neutron irradiated, respectively. The two irradiation samples were irradiated with slow neutrons and electrons at room temperature to a dosage of $1.0 \times 10^{15} \mathrm{n} / \mathrm{cm}^{2}$ and $4.5 \times 10^{15} \mathrm{e} / \mathrm{cm}^{2}$, respectively. Isochronal thermal annealing was performed in a nitrogen atmosphere between $350{ }^{\circ} \mathrm{C}$ and $1100{ }^{\circ} \mathrm{C}$ for $30 \mathrm{~min}$. The irradiated samples were stored at room temperature about two weeks before LTPL measurements.

LTPL measurements were performed at $3.5 \mathrm{~K}$ and $6 \mathrm{~K}$ using a $325 \mathrm{~nm}$ wavelength $\mathrm{He}-\mathrm{Cd}$ laser. The $\mathrm{He}-\mathrm{Cd}$ laser light was continuous wave and was linearly polarized with respect to the sample. The sample was mounted on the cold finger of a Janis closed cycle cryostat and was illuminated by the laser light, and the incident angle was smaller than $30^{\circ}$. The diameter of laser spot on the sample was estimated to be around $0.1 \mathrm{~mm}$. The laser power was adjusted from 0.5 to $16.8 \mathrm{~mW}$ for the variable excitation intensity PL measurement. The LTPL emission was analyzed with a SPEX750M single grating (1200 lines/mm) monochromater and was detected with a Hamamatsu R928 photomultiplier. The lock-in amplifier technology was employed in the setup for optimizing signal-to-noise ratio. The spectral resolution of the spectrometer was $0.1 \mathrm{~nm}$.

\section{RESULTS AND DISCUSSION}

A typical PL spectrum of an as-neutron-irradiated $n$-type $6 \mathrm{H}-\mathrm{SiC}$ sample is shown in Fig. 1(b). Three sets of stable dominant signals were clearly observed. One set of dominant signals is the lines of the well-known $4 \mathrm{~N} 0$ and the other is the lines labeled as $S_{1}, S_{2}$, and $S_{3}$. The former is related to 


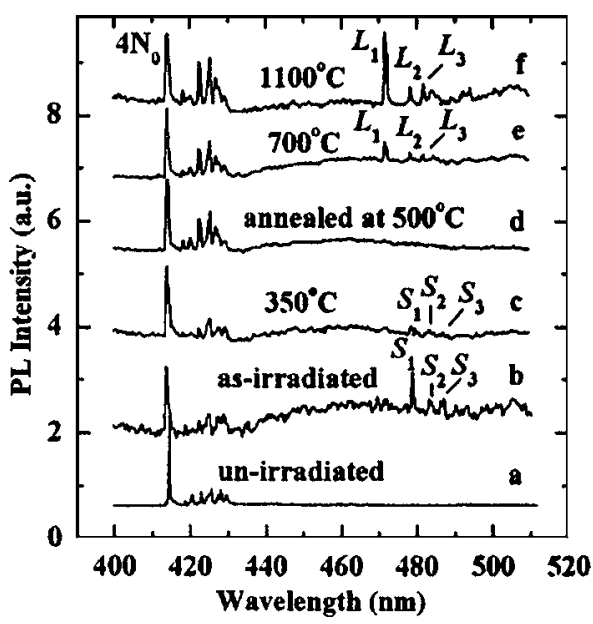

FIG. 1. LTPL spectra for $n$-type $6 \mathrm{H}$-SiC: (a) unirradiated sample at $6 \mathrm{~K}$; and (b)-(f) neutron-irradiated sample at $3.5 \mathrm{~K}$ before and after annealing.

bound exciton recombination at a four-particle neutral nitrogen donor at the three inequivalent lattice sites, which has been intensively investigated and clearly identified in Ref. 12 and is commonly used as an indicator for the presence of $\mathrm{N}$ dopants in $\mathrm{SiC}^{13}$ The LTPL emission lines $S_{1}, S_{2}, S_{3}$ at $478.6 \mathrm{~nm}, 483.3 \mathrm{~nm}, 486.1 \mathrm{~nm}$, respectively, were observed for the first time. These lines were not seen in the unirradiated sample in this range [Fig. 1(a)] and are very similar to the well-known $D_{1}$ center. Similar PL spectra were obtained for the electron-irradiated $n$-type $6 \mathrm{H}-\mathrm{SiC}$ as shown in Fig. 2.

The annealing behaviors of the irradiated samples were systematically studied as shown in Figs. 1(c)-1(f). After annealing at $350{ }^{\circ} \mathrm{C}$, the defect lines $S_{1}, S_{2}, S_{3}$ became weak and completely disappeared at $500{ }^{\circ} \mathrm{C}$. Another set of PL peaks emerged at $472.4 \mathrm{~nm}, 476.9 \mathrm{~nm}, 482.5 \mathrm{~nm}$ after a higher temperature $700{ }^{\circ} \mathrm{C}$ annealing. These lines $\left(L_{1}, L_{2}\right.$, and $L_{3}$ ) are the well-known $D_{1}$ center, which can withstand annealing up to $1600{ }^{\circ} \mathrm{C} .{ }^{11,13,14}$ It can be seen that the $S_{1}, S_{2}$, $S_{3}$ and the $D_{1}$ center are different since the PL lines of the latter located at $472.4 \mathrm{~nm}, 476.9 \mathrm{~nm}, 482.5 \mathrm{~nm}$ (corresponding to the three inequivalent lattice sites ${ }^{15}$ in $6 \mathrm{H}-\mathrm{SiC}$ ) only emerged after annealing at $700{ }^{\circ} \mathrm{C}$. It is thus most likely that the $S_{1}, S_{2}, S_{3}$ is a set of primary defects while the $D_{1}$ center

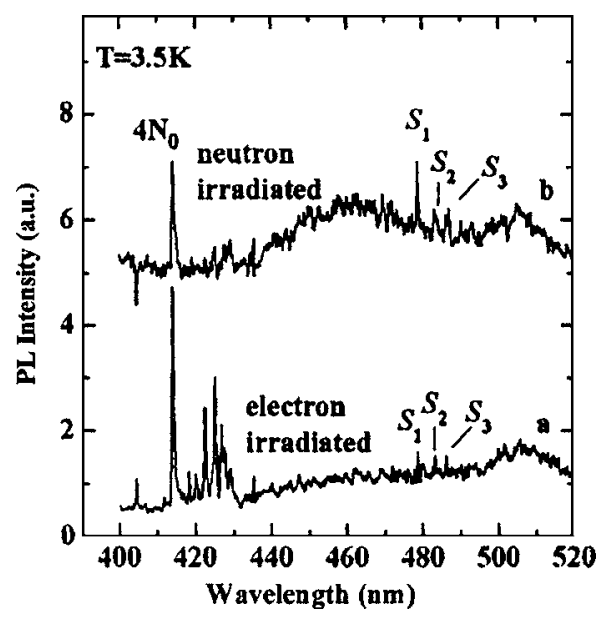

FIG. 2. LTPL spectra of $n$-type $6 \mathrm{H}-\mathrm{SiC}$ after neutron- and electron-irradiation. is a kind of secondary defect. However, no further information about their transition could be inferred since neither existed for quite a range of annealing temperature $\left(500{ }^{\circ} \mathrm{C}-700^{\circ} \mathrm{C}\right)$.

Although the $D_{1}$ center in $6 \mathrm{H}-\mathrm{SiC}$ was widely observed in the past, it was mostly in the context of ion implantation usually accompanied by high-temperature annealing (hence missing the low-temperature annealing features).,13,16 This may explain why only the $D_{1}$ center was observed in their works.

Egilsson et al. reported a set of the PL spectra $E_{A}$ in the region $4250-4500 \AA$ in the electron-irradiated $n$-type $4 \mathrm{H}$ SiC sample before annealing. ${ }^{17}$ This set of defects which annealed out at approximately $750{ }^{\circ} \mathrm{C}$ may well be similar to the defects $S_{1}, S_{2}, S_{3}$ reported here.

In previous works, the only defect with annealing temperature around $500{ }^{\circ} \mathrm{C}$ was the defect $H_{1}$ detected using DLTS in electron-irradiated $p$-type $6 \mathrm{H}-\mathrm{SiC}$, which seemed to be similar to this observation of the $S_{1}, S_{2}, S_{3} .{ }^{18}$ However, the $H_{1}$ did not exhibit any character of inequivalent sites as does $E_{1}, E_{2}$.

According to recent experimental and theoretical studies, the majority of initial defects introduced by irradiation were single vacancy $\left(V_{S i}\right.$ or $\left.V_{c}\right)$ related. ${ }^{19-21}$ In $\mathrm{SiC}$, both the silicon and carbon vacancies are stable at room temperature. ${ }^{22}$ Employing positron annihilation spectroscopy (PAS) measurement, Ling et al. pointed out that $V_{\mathrm{Si}}$ and $V_{c}$ would disappear after a $450{ }^{\circ} \mathrm{C}$ to $600{ }^{\circ} \mathrm{C}$ annealing. ${ }^{23}$ All these experimental results indicate that $S_{1}, S_{2}, S_{3}$ are possibly generated from single vacancy defects $\left(V_{S i}\right.$ or $\left.V_{c}\right)$, but their microstructures remain unidentified. Further studies on this topic are certainly necessary.

Many techniques, such as DLTS, PL, and PAS, have been employed to monitor the characteristics of irradiationinduced defects in $\mathrm{SiC}$ and a series of irradiation related defects have been reported. ${ }^{1-4}$ Annealing behaviors of these defects were investigated in order to understand the relationships among results from different techniques. For example, the defects $E_{1}, E_{2}$ from DLTS and the $D_{1}$ center were considered to be the same defect because of their similar thermal behaviors and character of inequivalent sites. However, as it has been pointed out, the family of irradiation-induced defects in $6 \mathrm{H}-\mathrm{SiC}$ seem to be very complicated due to their different thermal behaviors. ${ }^{1,18}$ The experimental results of this work have indicated that the $D_{1}$ center was a secondary defect produced in the annealing process while the defect $E_{1}$, $E_{2}$ existed in the as-irradiated materials.

The PL lines at $419-430 \mathrm{~nm}$ are the emission lines of 4N0 accompanied by its phonon replicas (as already reported). ${ }^{12,24}$ As for the as-neutron-irradiated samples, we think that there may well be competing (recombination) defects shunting the PL signal in question. Upon annealing, many of these defects killing the PL signal get annealed out allowing the PL lines to appear. This can explain why these spectral features appear for the neutron-irradiated samples only after annealing. The broad feature between $440 \mathrm{~nm}$ and $480 \mathrm{~nm}$ is systematic noise. However, in 1993, Pensl and Choyke reported PL signals in this range, ${ }^{12}$ the discrepancy was possibly due to the difference in $\mathrm{SiC}$ samples of the two 
studies, since the SiC samples used by Pensl et al. were early $\mathrm{SiC}$ materials and had more defects induced by the growth of $\mathrm{SiC}$ crystals.

\section{CONCLUSION}

In conclusion, a set of defects $S_{1}, S_{2}, S_{3}$ has been observed in as-neutron (electron) -irradiated $n$-type $6 \mathrm{H}-\mathrm{SiC}$ for the first time. These were completely annealed out after a $500{ }^{\circ} \mathrm{C}$ treatment. The $D_{1}$ center did not appear until after $700{ }^{\circ} \mathrm{C}$ annealing. These experimental results strongly indicate that the $D_{1}$ center is a secondary defect. Even with the very different thermal behaviors, it is still not possible to infer the microstructures of these defects and thus further studies are necessary.

\section{ACKNOWLEDGMENTS}

The work described in this paper was financially supported by the Grant of National Natural Science Foundation of China (No. 60076010), the Grant of Key Laboratory of Radiation Physics and Technology of Ministry of Education, HKSAR RGC CERG (under Projects No. HKU7085/01P, HKU7021/04P, and CEGR 7033/05P) and the HKU CRCG.

${ }^{1}$ M. Gong, S. Fung, C. D. Beling, and Z. You, J. Appl. Phys. 85, 7604 (1999).

${ }^{2}$ L. Patrick and W. J. Choyke, Phys. Rev. B 5, 3253 (1972).
${ }^{3}$ M. Weidner, T. Frank, G. Pensl, A. Kawasuso, H. Itoh, and R. KrauseRehberg, Physica B 308, 633 (2001).

${ }^{4}$ N. T. Son et al., Diamond Relat. Mater. 6, 1378 (1997).

${ }^{5}$ C. G. Hemmingsson, N. T. Son, O. Kordina, E. Janzén, and J. L. Lindström, J. Appl. Phys. 84, 704 (1998).

${ }^{6}$ J. P. Doyle, M. O. Aboelfotoh, B. G. Svensson, A. Schöner, and N. Nordell, Diamond Relat. Mater. 6, 1388 (1997).

${ }^{7}$ X. D. Chen et al., Phys. Rev. Lett. 92, 125504 (2004).

${ }^{8}$ X. D. Chen, C. C. Ling, M. Gong, S. Fung, C. D. Beling, G. Brauer, W. Anwand, and W. Skorupa, Appl. Phys. Lett. 86, 031903 (2005).

${ }^{9}$ W. J. Choyke, Inst. Phys. Conf. Ser. 31, 58 (1977).

${ }^{10}$ M. V. B. Pinheiro, T. Lingner, F. Caudepon, S. Greulich-Weber, and J. M. Spaeth, Mater. Sci. Forum 457-460, 517 (2004).

${ }^{11}$ T. Frank, G. Pensl, S. Bai, R. P. Devaty, and W. J. Choyke, Mater. Sci. Forum 338, 753 (2000).

${ }^{12}$ G. Pensl and W. J. Choyke, Physica B 185, 264 (1993).

${ }^{13}$ S. Fung et al., Physica B 308, 710 (2001).

${ }^{14}$ R. P. Devaty and W. J. Choyke, Phys. Status Solidi A 162, 5 (1997).

${ }^{15}$ T. Dalibor et al., Inst. Phys. Conf. Ser. 142, 517 (1995).

${ }^{16}$ Ch. Haberstroh, R. Helbig, and R. A. Stein, J. Appl. Phys. 76, 509 (1994).

${ }^{17}$ T. Egilsson, A. Henry, I. G. Ivanov, J. L. Lindström, and E. Janzén, Phys. Rev. B 59, 8008 (1999).

${ }^{18}$ M. Gong, S. Fung, C. D. Beling, and Z. You, J. Appl. Phys. 85, 7120 (1999).

${ }^{19}$ A. A. Rempel, W. Sprengel, K. Blaurock, K. J. Reichle, J. Major, and H.-E. Schaefer, Phys. Rev. Lett. 89, 185501 (2002).

${ }^{20}$ S. Arpiainen, K. Saarinen, P. Hautojarvi, L. Hebry, M.-F. Barthe, and C. Corbel, Phys. Rev. B 66, 075206 (2002).

${ }^{21}$ T. Linger, S. Greulich-Weber, and J. M. Spaeth, Phys. Rev. B 64, 245212 (2001).

${ }^{22}$ N. T. Son, P. N. Hai, and E. Janzén, Phys. Rev. B 63, 201201 (2001).

${ }^{23}$ C. C. Ling, C. D. Beling, and S. Fung, Phys. Rev. B 62, 8016 (2000).

${ }^{24}$ X. D. Chen et al., Solid State Commun. 121, 67 (2002). 